\title{
BENEFITS OF NORDIC WALKING
}

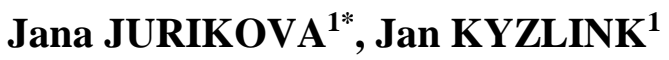 \\ ${ }^{1}$ Masaryk University, Faculty of Sports Studies, Department of Kinesiology, Brno, Czech Republic \\ *Corresponding author: jurikova@fsps.muni.cz
}

https://doi.org/10.35189/dpeskj.2020.59.s.1

\begin{abstract}
Nordic Walking improves physical fitness more than walking without poles. This is due to the fact that Nordic Walking involves more muscles during exercise. Experimental results show that around $90 \%$ of muscles are activated during Nordic Walking with the correct technique. Performing Nordic Walking influences the reduction of body weight and improves all biochemical parameters relevant to diabetes. This paper aims to find common knowledge about the benefits of Nordic Walking on the human body. The information was found through questionnaires. The research involved 74 people -47 men and 27 women with an average age of 38.67 \pm 18.09 years. The questionnaires were fully anonymous. The majority of respondents $(79.7 \%)$ are already somehow familiar with Nordic Walking, most of them (33.8\%) knowing someone who practises Nordic Walking in the city. 23\% of respondents have tried Nordic Walking, but only $10.8 \%$ keep performing it. According to the majority of respondents (77\%), Nordic Walking is a proper activity for all age groups and they would recommend it to their parents and grandparents due to its benefits on human health. Most respondents (85.1\%) believe that Nordic Walking is beneficial for human health only to prevent diseases of the muscle system and as a consequent rehabilitation method. Nordic Walking has no influence on human health from the point of view of the rest of respondents. Nordic Walking is just a pleasant way to enjoy in one's free time. This might be changed by the continuing education of the general public.
\end{abstract}

Keywords: Nordic Walking, benefits, health, sport.

\section{Introduction}

In these fast-moving days, people abandon their interest in hiking connected with various sport performances, but especially the sport itself. This is true not only for young people and children, but also for adults. It does not matter whether it is alpine tourism or common leisure walk, people are more and more bound by cities, careers and daily duties and hardly have any time for active pastime. The lower interest in sport is obvious in childhood, most likely due to low motivation and poor support from parents and mainly due to the growing influence of electronic gadgets and computer technologies. This situation results in health problems at a later age, overweight or obesity and other civilization diseases.

Nordic Walking is a fitness activity with a universal effect on a person and, above all, it positively influences health. In comparison with ordinary walk (without poles), it requires about $22 \%$ higher energy expenditure, heart rate is $16 \%$ higher and it involves $90 \%$ of all muscles. This makes Nordic Walking significantly more effective than normal walk. It is a unique way to decrease body weight, increase physical condition, improve body posture and relieve back pain. As an outdoor activity, Nordic Walking is a great relaxation technique and can be practised in pairs or group, which makes it a social event too. (Sovová et al., 2008)

Nordic Walking is suitable for all age categories due to the variable form of intensity and various fitness programmes. It can be back pain prevention or therapy, or fitness improvement and energy burn-out, or simply the enlivening of other hiking activities. Nordic Walking 
belongs to stamina activities with elements of power and explosiveness and can be performed almost all life; it is suitable for both children and seniors. Its great advantage is the intensity that can be adjusted to an individual and also the choice of location, which is wide, ranging from paved roads to hilly rocky routes.

\section{History and origin of Nordic Walking}

The origin of Nordic Walking is ascribed to a coincidence. As obvious from the name, it comes from the North, particularly Finland. In 1988, thanks to Tuom Jantunem, a 5-km crosscountry skiing competition was organized in Helsinki on the occasion of unveiling the statue of Lauri Pihkala. Unfortunately, just before the competition started, all the snow had melted. Organizers did not want to cancel the event, so they agreed on the classic run without skis, but with poles. The total number of runners was about 50 . The first documented point in the history of Nordic Walking is this cross-country skiing race held in 1988. (Hadová, 2013)

Besides Scandinavian countries, Nordic Walking became spread in other countries too, including the USA. At the beginning of the 80's, particularly in the USA, there was an effort to enrich "ordinary" walk with the simultaneous movement of upper extremities and the trunk. In the 90's, in the USA, a phenomenon called "Pole walking" (walking with poles) emerged. The place of origin of walking with special poles is Finland where, in 1997, the first special poles for this sport activity were manufactured. (Sovová et al., 2008)

\section{Comparison between ordinary walk and Nordic Walking}

Walking is a fundamental locomotor movement in all humans. It has been the main way to overcome distances since the beginning of human existence. People used to go hunting, collect food, travel distances, discover, commute for a job and many other activities. Nowadays, due to cars and other transport vehicles, walking is losing its significance. There is no doubt, it is the movement without which we could not live, but long-distance walk is slowly diminishing, even though it is the most economical activity that is for free and is beneficial to our health. Currently, people mostly struggle for time, so cars and public transport are more convenient and widely used. Children are taken to school by their parents' cars, and adults use public transport. All this is reflected in the public health of the population. (Sovová et al., 2008)

According to Smith and Levin (1995), most people consider walking as seniors' sport activity. In fact, it is suitable for all age categories, from children to seniors. It is suitable for people with poor physical condition, but also for fit people. Walking is easy; it does not bring any health risks. It is gentle for bones and joints and can be adjusted to the physical and health condition of an individual. Depending on the chosen pace, it can represent low intensity (5$6.5 \mathrm{~km} /$ hour $)$ to high intensity $(6.5-8 \mathrm{~km} /$ hour $)$ exercise. The better the physical condition, the faster the pace should be chosen to optimise benefits for the cardiovascular system. The character of ordinary walk and also Nordic Walking is determined by the terrain and surface. While asphalt or grass does not have any resistance, walking on a terrain such as a field is 1.5 more demanding. Concerning the fact that Nordic Walking is a year-round activity, a sporty person can also face a snowy terrain. Walking on hard snow is 1.6 and in deep soft snow even 3 times more demanding. A sandy terrain is approximately 1.8 times more demanding. Energy 
expenditure is growing with difficulty of the terrain. Conversely, walking downhill lowers energy expenditure by $25 \%$ in comparison with walking uphill. (Sovová et al., 2008)

Walking is ideal as a gentle start-up for sedentary people, including inactive, immobile elderly, bringing a bonus of independence and social well-being. As a general policy, gradual progression is indicated from slow to regular pace and 30 minutes or more of brisk walking (i.e. $6.4 \mathrm{~km} / \mathrm{h}$ ) on most days. (Morris \& Hardman, 1997) Brisk walking is protective of physical health, particularly if done consistently (Wagner et al., 2001), with health effects independent of the benefits of more vigorous activities (i.e. those traditionally considered exercise, such as running, swimming) (Manson et al., 1999; Sallis et al., 2004).These levels should achieve major gains in activity and health-related fitness without adverse effects. Alternatively, such targets can be suggested for personal motivation, clinical practice and public health. The average middle-aged person should be able to walk $1.6 \mathrm{~km}$ on the level at $6.4 \mathrm{~km} / \mathrm{h}$ and on a slope of 1 in 20 at $4.8 \mathrm{~km} / \mathrm{h}$, however, many cannot do so because of inactivity-induced unfitness. The physiological threshold of comfort represents $70 \%$ of maximum heart rate. (Morris \& Hardman, 1997)

Energy expenditure of different sport activities is given in Table 1.

Table 1. Energy expenditure of different sport activities

\begin{tabular}{lc}
\hline \multicolumn{1}{c}{ Sport activity } & Energy expenditure $(\mathrm{kJ} / \mathrm{h})$ \\
\hline Walk without poles, speed $3 \mathrm{~km} / \mathrm{h}$ & $700-850$ \\
Walk without poles, speed $4 \mathrm{~km} / \mathrm{h}$ & $800-1,000$ \\
Walk without poles, speed $5 \mathrm{~km} / \mathrm{h}$ & $1,000-1,300$ \\
Walk without poles, speed $6 \mathrm{~km} / \mathrm{h}$ & $1,300-1,600$ \\
Nordic Walking & $1,600-2,000$ \\
Cross-country skiing & $2,100-2,500$ \\
Downhill skiing & $1,900-2,100$ \\
Jogging & $2,100-2,500$ \\
Aerobic & $1,100-2,500$ \\
Swimming & $1,300-4,400$ \\
Cycling & $800-2,500$ \\
Skating & $1,900-2,000$ \\
Horse riding & $750-2,300$ \\
\hline
\end{tabular}

Source: Bítek, 2008; Fialová, 2007 - managed by authors

Active transport is most often defined as walking, cycling or other human-powered modes of transport (in-line skating, skateboarding) used for practical purposes of getting from one place to another in everyday life (Sallis et al., 2004). Active transport is also perceived as an easy and effective tool to increase the level of daily physical activity (Owen et al., 2004; Pavelka et al., 2012).

Further research confirmed the beneficial influence of pole walking on the human body. Porcari et al. (1997) examined men and women on athletic treadmill and indicated that using poles led to increases in oxygen intake, heart rate and energy expenditure compared to people walking without poles. Rodgers et al. (1995) noticed that 24-year-old women walking with poles during a 30-minute submaximal session exhibited higher levels of $\mathrm{VO}_{2}$ max than during the same session without poles. Their heart rate raised as well. Moreover, women walking with poles burnt more calories during a 30-minute session. More scientists obtained similar results 
with regards to the same parameters. They also noticed the increase of lactic acid during pole walking, which indicated a more intense physical exercise (Piech et al., 2014).

Nordic Walking has many characteristics that are similar to cross-country skiing (Vahasoyrinki et al., 2008), similar temporal and spatial profile of body part movements (Stoggl et al., 2007), similar development of the major motor skills and involvement of the same muscle groups (Dziuba et al., 2015).

\section{Nordic Walking for health}

Public health recommendations for physical activity tend to emphasise ordinary physical activities, particularly walking and bicycle riding as means of active transport. Active transport is considered an important source of natural physical activity and legal conditions: children and youth do not drive cars yet and, for senior citizen, walking is one of the most beneficial forms of physical activity. Hence, walking is recommended to Czech pupils and students as the most suitable mode of transport to school. A young person should make 10000 to 11000 steps per day on average. According to a survey among Czech secondary school students, overweight and obese individuals walk significantly less than their peers with an optimum weight (Mužík et al., 2010).

The DHHS (2008) published the Physical Activity Guidelines for Americans (PAG), suggesting the important influence of physical activity behaviours on health outcomes. The PAG were developed based on the evidence relating fitness, physical activity and energy expenditure to health outcomes. Guidelines for children and adolescents are daily physical activity behaviours of 60 minutes or more. The physical activity behaviours should include a minimum of three days per week of aerobic, muscle-strengthening and bone-strengthening activities (Morrow et al., 2013).

The use of walking as an elementary form of transport may play an important clinical role during patient rehabilitation, particularly for older people and physically or psychologically disadvantaged individuals. The benefits of regular walking can also be seen in some professionals such as postmen and women, who have a lower prevalence of cardiovascular diseases and hypertension than, for instance, typical sedentary professions such as officers or assembly line workers. Walking at all levels of intensity means energy output and therefore it is an unfailing method of weight and obesity reduction. Moreover, it is the most natural way of maintaining the function and strength of skeletal muscles and energy exchange. There are two types of effects of walking: short term and long term, which become apparent in weeks, months or years as a result of a regular habitual physical activity (Morris \& Hardman, 1997).

In 1990, a marked change arose in designing these guidelines. Emphasis was placed on physical activity related to the state of health and health in general, not only on fitness and physical performance as we have found in most previous studies (Sigmund et al., 2005). For this reason, emphasis is put on moderate physical activity (4-6 METs) (Corbin et al., 2004), which also contributes to the reduction of risk factors for some chronic diseases and is closer to the broad nonsporting population (Sigmund et al., 2005). Numerous observational studies have shown that the short-term benefits of Nordic Walking compared to brisk walking without poles include an increased $\mathrm{VO}_{2}$ max of 11-23\%, peak heart rate of 4-18\% (Rodgers et al., 1995; Porcari et al., 1997; Jordan et al., 2001; Church et al., 2002; Schiffer et al., 2006), respiratory 
exchange ratio of 5\% (Rodgers et al., 1995), lactate concentration of 12\% (Tschentscher et al., 2013), and caloric expenditure of 18-22\% (Rodgers et al., 1995; Porcari et al., 1997; Jordan et al., 2001). Nordic Walking generates up to 6.3-7.7 MET (Porcari et al., 1997) at brisk paces, whereas walking reaches 3.3-5.0 MET (Ainsworth et al., 2000). Nordic Walking over the longterm leads to superior cardiorespiratory fitness as compared to walking without poles because of the higher amount of muscle mass used through additional motor activity of the upper body. This results in an increased cardiovascular and respiratory response when walking at the same pace, causing increased energy expenditure (Kukkonen-Harjula et al., 2007). Up to a pace of $8.5 \mathrm{~km} / \mathrm{h}$ (i.e. $2.4 \mathrm{~m} / \mathrm{s}$ ), it even leads to similar or higher values of $\mathrm{VO}_{2}$ max and heart rate than jogging (Schiffer et al., 2006; Tschentscher et al., 2013).

And contrary to other physical activities, it is not limited to any significant degree by age, can be adapted to seasonal changes of weather, is independent on the will of surrounding environment and can be practiced almost anywhere at any time. Walking is probably the most readily available and, at the same time, highly effective means to prevent the malignant consequences of a sedentary lifestyle because it can, inter alia, induce a strong feeling of wellbeing. Regular walking and well-being are two interrelated phenomena.

Walking and Nordic Walking represent sport activities suitable for pregnant women too. These are both gentle on joints and therefore they stand for ideal endurance sports at the time of pregnancy. Both activities are similar in nature, and their popularity has recently increased. It is however essential to strain oneself. The great advantage of both sports is the fact that one leg always remains in contact with the ground. If a pregnant woman walks using her hands actively, with high intensity, or uses the poles, she activates up to $90 \%$ of all body muscles. Conscious movements with poles keep the body in the upright posture and thus decrease the burden to back muscles (Huch, 2007; Juříková \& Havelka, 2018).

The Internet websites often contain unverified reports claiming that Nordic Walking contributes to increased energy consumption (by over 40\%), higher efficiency and higher heart rate compared to ordinary walking (Hansen et al., 2008), and even that Nordic Walking reduces the load to the lower limbs (Kreuzriegler et al., 2002). However, the results are contradictory. Some reports have demonstrated the beneficial effect of Nordic Walking on hip, knee and ankle joints through reduced load to these points; on the other hand, there are studies showing that the use of poles does not change the load to the lower limbs (Hansen et al., 2008). Verifying the information about the actual reduction of load to the lower limbs during Nordic Walking is essential for Nordic walkers with obesity, the elderly and those with knee joint pain or osteoarthritis (Dziuba el al., 2015).

\section{Methodology}

The survey was carried out by the questionnaire method. We used the authors' questionnaire designed within the Department of Kinesiology of the Faculty of Sport Studies, Masaryk University. The questionnaire consists of 16 items. The introductory part focuses on the respondents' anthropometric parameters, the next questions aiming at their theoretical knowledge about Nordic Walking. Each respondent is also asked to report whether they perform Nordic Walking and other related questions. The questionnaire was electronically 
created using the Survio application (Survio, n.d.) and also electronically distributed to the public of all age categories. The questionnaire was anonymous.

The total number of respondents who filled in the questionnaire was 75 , but one was incomplete and thus had to be eliminated. Therefore, the questionnaire was properly filled in by 74 respondents ( 27 men and 47 women), whose average age was $38.67 \pm 18.09$ years.

This study deals only with some items of the questionnaire.

\section{Results}

One of the questions asked the respondents whether they were familiar with the term Nordic Walking. Their responses are shown in Table 2.

Table 2. Awareness of the term Nordic Walking

\begin{tabular}{lcc}
\hline \multicolumn{1}{c}{ Response } & Number of respondents & Number of respondents in \% \\
\hline Yes, I have heard of Nordic Walking & 59 & 79.7 \\
No, I have not heard of Nordic Walking & 15 & 20.3 \\
Total & 74 & 100.0 \\
\hline
\end{tabular}

Source: Study of authors

From the responses, it is obvious that most respondents have heard of Nordic Walking. The next question was directly related to this one, focusing on the source where the respondent found the information. Responses are shown in Figure 1.

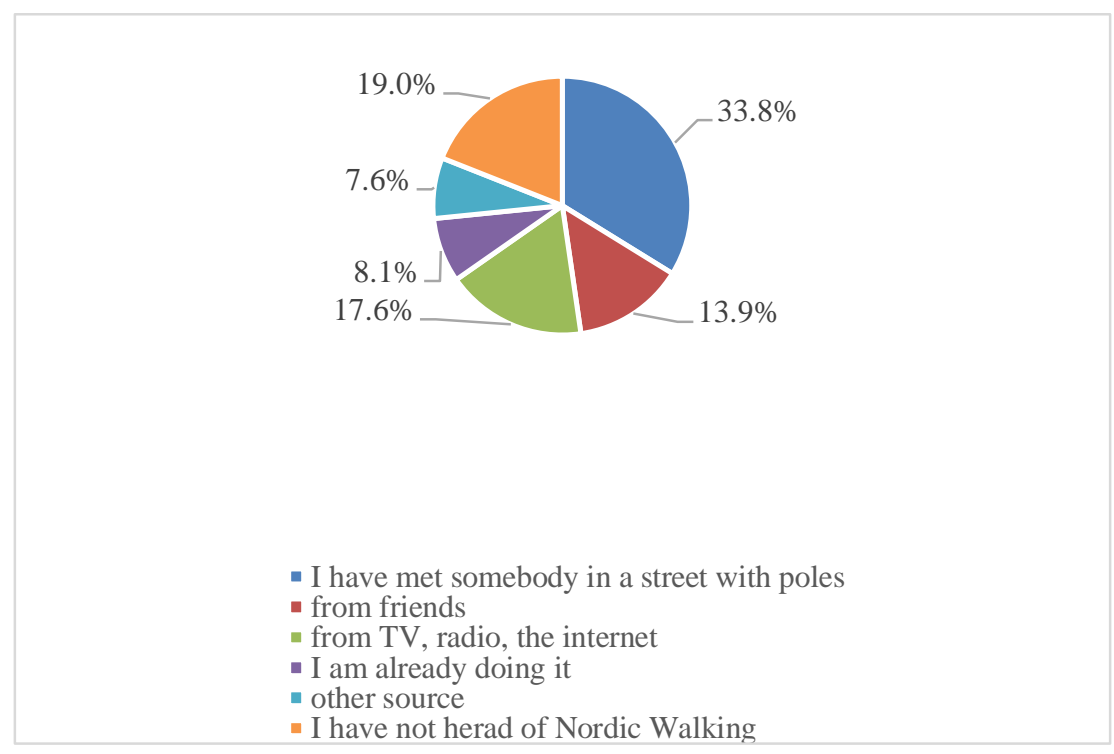

Figure 1. Information source where respondents found out about Nordic Walking Source: Study of authors

As obvious from the graph, most respondents (33.8\%) found out about Nordic Walking simply, meeting a person in a street with poles. Media, such as television, radio or the Internet, was the main information source for $17.6 \%$ of respondents. 1 respondent reported another source, namely a Physical Education course. 
Another question attempted to find out whether respondents have tried Nordic Walking on their own. Their responses are summarised in Table 3.

Table 3. Number of persons who have already tried Nordic Walking

\begin{tabular}{|c|c|c|}
\hline \multirow{2}{*}{$\begin{array}{l}\text { Response to the question whether the participant has tried } \\
\text { Nordic Walking }\end{array}$} & \multicolumn{2}{|c|}{ Number of respondents } \\
\hline & Number & $\%$ \\
\hline Yes & 17 & 23.0 \\
\hline No & 57 & 77.0 \\
\hline Total & 74 & 100.0 \\
\hline
\end{tabular}

Source: Study of authors

As apparent from the table, most respondents had tried Nordic Walking before. Given that the questionnaire was distributed electronically, it might have been predictable that this issue would rather appeal to people who have experience or actively perform this activity, which was the matter of the following question. Responses to the question whether participants actively perform Nordic Walking or are going to start it in the future are given in Table 4 and Figure 2.

Table 4. Respondents' interest in Nordic Walking activity

\begin{tabular}{lcc}
\hline \multirow{2}{*}{ Respondents' interest in Nordic Walking activity } & \multicolumn{2}{c}{ Number of respondents } \\
\cline { 2 - 3 } & Number & $\%$ \\
\hline Yes, I'm already doing it & 8 & 10.8 \\
Yes, I'm going to start it in the future & 9 & 12.2 \\
I don't know, I haven't tried Nordic Walking yet & 51 & 68.9 \\
No, I'm not interested in & 6 & 8.1 \\
Total & 74 & 100.0 \\
\hline
\end{tabular}

Source: Study of authors

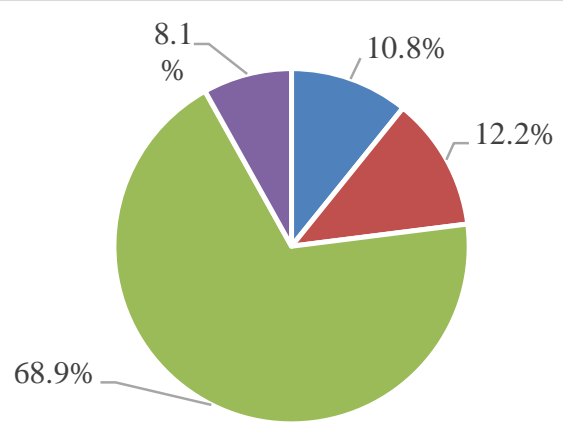

- Yes, I'm already doing it

- Yes, I'm going to start in future

- I don't know, I haven't tried NW yet

- No, I'm not interested

Figure 2. Respondents' interest in Nordic Walking activity Source: Study of authors 
As we can see from the table and graph, of all respondents with Nordic Walking experience (17 persons in total), about a half ( 8 persons) perform it actively. The remaining 9 respondents consider Nordic Walking as a possible activity for the future. No one denied Nordic Walking after their first experience. Of the total number of persons who have not tried Nordic Walking yet (59 persons), merely 6 persons $(8.1 \%)$ stated that they were not going to try it in the future at all, since they did not find it attractive enough.

The next question examined to whom respondents would recommend Nordic Walking. They were given several options and could choose more of them or use their own response. Participants' responses are given in Figure 3.

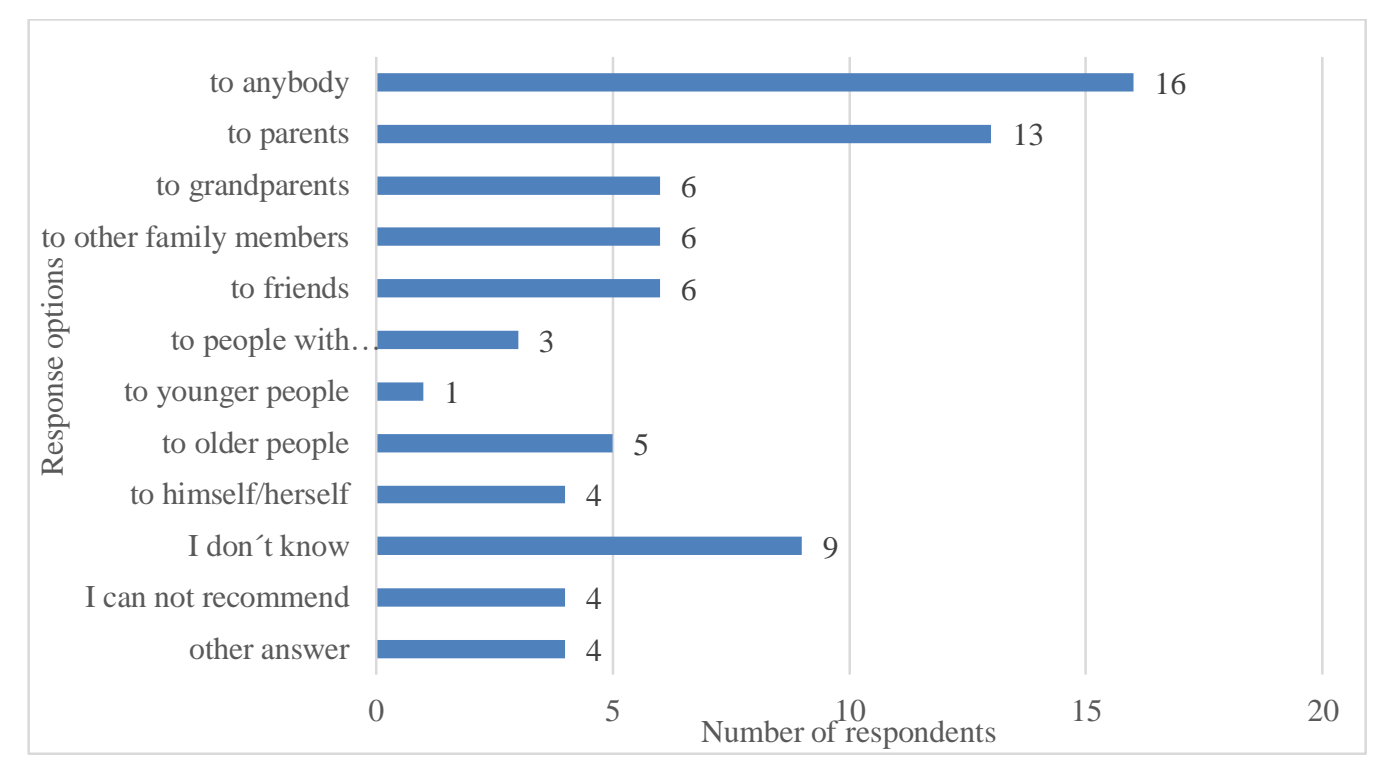

Figure 3. To whom Nordic Walking can be recommended, according to respondents Source: Study of authors

As obvious from the graph, most respondents would recommend Nordic Walking to anybody, which we can absolutely agree with, since Nordic Walking is suitable for all age categories. Walking makes up the largest part of physical activities in adolescence, about $60 \%$, and is considered to create a pedestrian-friendly environment. This can be achieved most effectively by ensuring varied landscapes and close opportunities for walking to work, shops or leisure centres. Eleven respondents are probably of the opinion that Nordic Walking is more suitable for older age, therefore they would recommend it to their parents (13 persons) or grandparents (6 persons). Nordic Walking is a suitable form of aerobic exercise for most of apparently healthy male and female subjects aged 40-60 years, who would benefit from training at a proper aerobic exercise intensity between 4-8 METs, an intensity range that is too high to obtain by regular walking and too low to achieve while running. In these subjects, Nordic Walking is suitable to close the intensity gap between walking and jogging and thus presents an alternative for everybody seeking a sport of an intensity that results in gaining health benefits while exceeding personal exertion limits. Twelve weeks of Nordic Walking demonstrated a decrease in BMI, total fat mass, low-density lipoproteins, triglycerides and waist circumference and an increase in high-density lipoproteins in otherwise healthy postmenopausal women. 
(Hagner et al., 2009; Figard-Fabre et al., 2011; Tschentscher et al., 2013) Nordic Walking is an attractive method of endurance training. Nevertheless, the biomechanical response due to the additional contribution of using poles in relation to free-walking training has been less explored in the elderly. (Gormeňuka et al., 2020)

Nordic Walking plays a significant role in enhancing seniors' physical condition and thus their self-sufficiency, however it is convenient for people of all ages. For the option "Other response", we find: a sporty person, people who like hiking, people who like brisk walks, people with joint health problems, to relieve (the activity strengthens the whole body). Also, these responses can be agreed with, particularly the last option which includes health benefits of Nordic Walking. The last question focuses on finding out whether Nordic Walking is suitable for people with health problems. Responses are shown in Table 5 and Figure 4.

Table 5. Suitability of Nordic Walking for people with health problems, according to respondents

\begin{tabular}{lcc}
\hline Suitability of Nordic Walking for people with health problems, & \multicolumn{2}{c}{ Number of respondents } \\
\cline { 2 - 3 } according to respondents & Number & $\%$ \\
\hline Yes, it is suitable as prevention and physiotherapy & 63 & 85.1 \\
Yes, it is suitable for any person, but has no influence on health & 3 & 4.1 \\
No, it is not suitable for persons with health problems & 8 & 10.8 \\
I do not know & 0 & 0 \\
Other option & 0 & 0 \\
Total & 74 & 100.0 \\
\hline
\end{tabular}

Source: Study of authors

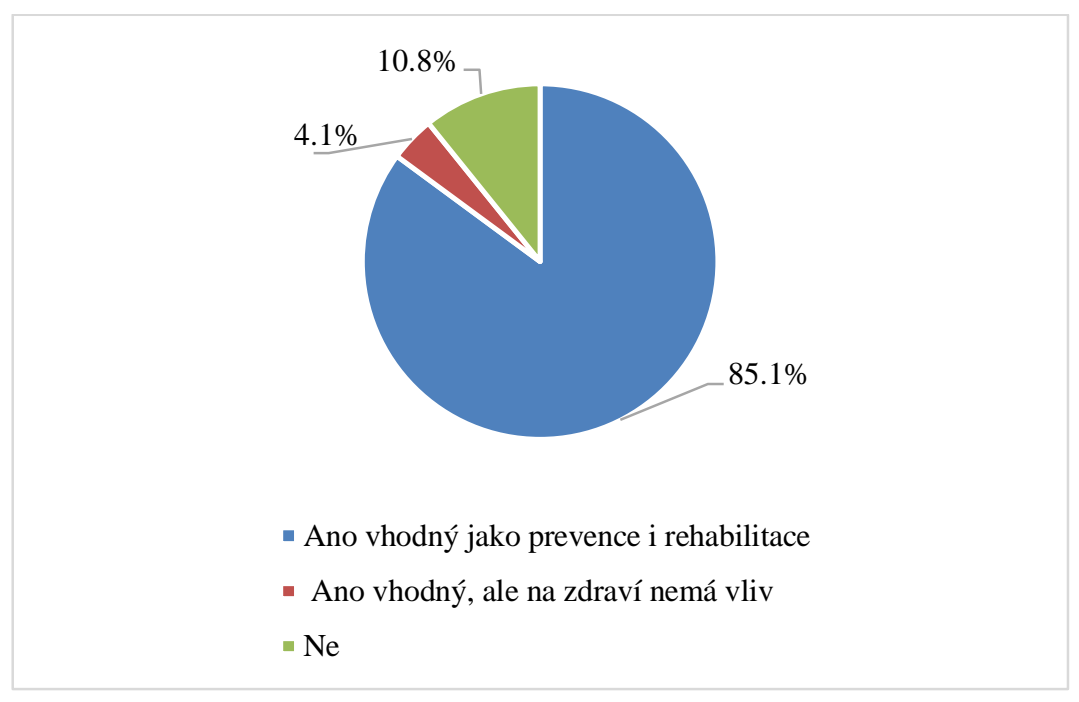

Figure 4. Suitability of Nordic Walking for people with health problems, according to respondents

Source: Study of authors

As obvious from the graph and table, most respondents $(85.1 \%)$ are aware of the health benefits of Nordic Walking. 4.1\% of them are of the opinion that Nordic Walking is a convenient physical activity (Kyzlink, 2018), but does not have any influence on the health condition, which is not true. Nordic Walking is recommended to all people, including those 
with health problems, especially for its health benefits and for improving overall physical condition. Among its main advantages, we can mention the specific transfer of body gravity, which does not change at the vertical level. This results in lower strain to the knee joints, back and lower part of the spine. Moreover, due to the proper work with poles, part of the body weight is directed to the upper part of the trunk. The technique of releasing the pole followed by its grip using special gloves puts a strain to the upper extremities, which lowers the strain in the upper part of the spine and consequently lowers the pressure to the spinal discs.

\section{Conclusion}

The study focuses on the general awareness of Nordic Walking by the common population in the Czech Republic. The information from respondents was collected by the questionnaire method. $79.7 \%$ of respondents are aware of Nordic Walking, they mostly learn about it simply by meeting a person with poles - this response was given by $33.8 \%$ of participants. $23 \%$ of respondents have their own experience with Nordic Walking, but merely $10.8 \%$ keep doing this activity, and $12.2 \%$ of respondents consider it as a possible activity for the future. When asked to whom they would recommend Nordic Walking, most respondents said that to all people, which is correct, since Nordic Walking is suitable for all age categories. The question whether Nordic Walking is suitable for people with health problems was mostly responded correctly $(85.1 \%)$, namely that Nordic Walking, due to its health benefits, is also suitable for people with health problems. It is just necessary to adjust difficulty and the length of the track.

Awareness of respondents who submitted completed questionnaires is sufficient, although higher public response would be welcome. This should be reached through relevant education.

\section{References}

Ainsworth, B. E., Haskell, W. L., Whitt-Glover, M. C., Irwin, M. L., Swartz, A. M., Strath, S. J., O’Brien, W. L., Bassett Jr, D. R., Schmitz, K. H., Emplaincourt, P. O., Jacobs Jr, D. R., $\&$ Leon, A. S. (2000). Compendium of physical activities: An update of activity codes and MET intensities. Medicine \& Science in Sports \& Exercise, 32(9 Suppl), S498-504. https://doi.org/10.1097/00005768-200009001-00009

Corbin, C. B., Pangrazi, R. P., \& Le Masurier, G. C. (2004). Physical activity for children: Current patterns and guidelines. Journal of Physical Activity \& Health, 1(3). https://doi.org/10.1123/jpah.1.3.281

Church, T. S., Earnest, C. P., \& Morss, G. M. (2002). Field testing of physiological responses associated with Nordic Walking. Research Quarterly for Exercise and Sport, 73(3), 296300. https://doi.org/10.1080/02701367.2002.10609023

DHHS. (2008). Physical activity guidelines for Americans. Washington DC: DHHS.

Dziuba, A. K., Zurek, G., Garrard, I., \& Wierzbicka-Damska, I. (2015). Biomechanical parameters in lower limbs during natural walking and Nordic Walking at different speeds. Acta of Bioengineering and Biomechanics, 17(1), 95-101. doi: 10.5277/ABB-00077-2014-01

Figard-Fabre, H., Fabre, N., Leonardi, A., \& Schena, F. (2011). Efficacy of Nordic Walking in obesity management. International Journal of Sports Medicine, 32(6), 407-414. https://doi.org/10.1055/s-0030-1268461 
Gormeňuka, N. A., Oliveira, H. B., da Silva, E. S., Passos-Monteiro, E., da Rosa, R. G., Carvalho, A. R., Costa, R. R., Paz, M. C. R, Pellegrini, B., \& Peyré-Tartaruga, L. A. (2020). Nordic Walking training in elderly, a randomized clinical trial. Part II: Biomechanical and metabolic adaptations. Sports Medicine Open, 6(1): 3.

https://doi.org/10.1186/s40798-019-0228-6

Gotowski, R., Juř́íková, J., \& Muszkieta, R. (2018). Nordic Walking: Wybrane aspekty [Nordic Walking: Chosen aspects]. Bydgoszcz-Toruń: Sportu i Edukacji w Poznaniu, Akademia Sportu i Nauki w Bydgoszczy.

Hadová, J. (2013). Nordic walking pro radost [Nordic Walking for fun]. https://www.nwproradost.cz/o-nordic-walkingu/historie/

Hansen, L., Henriksen, M., Larsen, P., \& Alkjaer, T. (2008). Nordic Walking does not reduce the loading of the knee join. Scandinavian Journal of Medicine and Science in Sports, 18(4), 436-441. https://doi.org/10.1111/j.1600-0838.2007.00699.x

Huch, R. (2007). Št’astné těhotenství od A do Z [Happy pregnancy from A to Z]. Praha: Grada. Hagner, W., Hagner-Derengowska, M., Wiacek, M., \& Zubrzycki, I. Z. (2009). Changes in level of $\mathrm{VO}_{2} \max$, blood lipids, and waist circumference in the response to moderate endurance training as a function of ovarian aging. Menopause: The Journal of North American Menopause Society, 16(5), 1009-1013. https://doi.org/10.1097/gme.0b013e31819c0924

Jordan, A. N., Olson, T. P., Earnest, C. P., \& Morss, G. M. (2001). Metabolic cost of high intensity poling while Nordic Walking versus normal walking. Medicine \& Science in Sports \& Exercise, 33(5): S86. https://doi.org/10.1097/00005768-200105001-00496

Juř́ková, J., \& Havelka, R. (2018). Nordic Walking in pregnant women. In R. Gotowski et al., Nordic Walking: Wybrane aspekty [Nordic Walking: Chosen aspects] (pp. 14-20). Bydgoszcz-Toruń: Sportu i Edukacji w Poznaniu, Akademia Sportu i Nauki w Bydgoszczy.

Kreuzriegler, F., Gollner, E., \& Fichtner, H. (2002). Das ist Nordic Walking: Ausrustung, Technic, Training [This is Nordic Walking: Equipment, Technique, Training]. MünchenJena: Urban \& Fischer.

Kukkonen-Harjula, K., Hiilloskorpi, H., Mänttäri, A. T., Pasanen, M., Parkkari, J., Suni, J., Fogelholm, M., \& Laukkanen, R. (2007). Self-guided brisk walking training with or without poles: A randomized-controlled trial in middle-aged women. Scandinavian Journal of Medicine and Science in Sports, 17(4), 316-323. https://doi.org/10.1111/j.1600-0838.2006.00585.x

Kyzlink, J. (2018). Nordic Walking jako forma aktivní dovolené [Nordic Walking as a form of active rest]. Brno: Masaryk University, Faculty of Sports Studies.

Manson, J. E., Hu, F. B., Rich-Edwards, J. W., Colditz, G. A., Stampfer, M. J., Willett, W. C., Speizer, F. E., \& Hennekens, C. H. (1999). A prospective study of walking as compared with vigorous exercise in the prevention of coronary heart disease in women. The New England Journal of Medicine, 341(9), 650-658. https://doi.org/10.1056/nejm199908263410904

Morris, J. N., \& Hardman, A. E. (1997). Walking to health. Sports Medicine, 23(5), 306-332. https://doi.org/10.2165/00007256-199723050-00004

Morrow Jr, J. R., Trucker, J. S., Jackson, A. W., Martin, S. B., Greenleaf, C. A., \& Petrie, T. A. (2013). Meeting physical activity guidelines and health-related fitness in youth. American Journal of Preventive Medicine, 44(5), 439-444. https://doi.org/10.1016/j.amepre.2013.01.008

Mužík, V., Forejt, M., Matějová, H., Mužíková, L., Gottvaldová, E., Hlavatá, K., Košt’álová, A., Kubrichtová, L., Sovinová, H., \& Škaloudová, L. (2007). Výživa a pohyb jako součást výchovy ke zdravi na základní škole [Nutrition and exercise as part of health education in primary school]. Brno: Paido. 
Owen, N., Humpel, N., Leslie, E. Bauman, A., \& Sallis, J. F. (2004). Understanding environmental influences on walking review and research agenda. American Journal of Preventive Medicine, 27(1), 67-76. https://doi.org/10.1016/j.amepre.2004.03.006

Pavelka, J., Sigmundová, D., Hamř́ik, Z., \& Kalman, M. (2012). Active transport among Czech school-aged children. Acta Universitatis Palackianae Olomucensis. Gymnica, 42(3), 17-26. doi: 10.5507/ag.2012.014

Piech, K., Piech, J., \& Grants, J. (2014). Nordic Walking: A versatile physical activity fit for everyone (A literature review). LASE Journal of Sport Science, 5(1), 46-56. https://doi.org/10.1515/LJSS-2016-0025

Porcari, J. P., Hendrickson, T. L., Walter, P. R., Terry, L., \& Walsko, G. (1997). The physiological responses to walking with and without Power Poles ${ }^{\mathrm{TM}}$ on treadmill exercise. Research Quarterly for Exercise and Sport, 68(2), 161-166. https://doi.org/10.1080/02701367.1997.10607992

Rodgers, C. D., Vanheest, J. L., \& Schachter, C. L. (1995). Energy expenditure during submaximal walking with Exerstriders. Medicine \& Science in Sports \& Exercise, 27(4), 607-611. https://doi.org/10.1249/00005768-199504000-00021

Sallis, J. F., Frank, L. D., Saelens, B. E., \& Kraft, M. K. (2004). Active transportation and physical activity: Opportunities for collaboration on transportation and public health research. Transportation research Part A: Policy and practice, 38(4), 249-268. https://doi.org/10.1016/j.tra.2003.11.003

Schiffer, T., Knicker, A., Hoffman, U., Harwig, B., Hollmann, W., \& Strüder, H. K. (2006). Physiological responses to Nordic Walking, walking and jogging. European Journal of Applied Physiology, 98(1), 56-61. https://doi.org/10.1007/s00421-006-0242-5

Sigmund, E., Frömel, K., \& Neuls, F. (2005). Physical activity of youth: Evaluation guidelines from the viewpoint of health support. Acta Universitatis Palackianae Olomucensis. Gymnica, 35(2), 59-66. https://www.gymnica.upol.cz/pdfs/gym/2005/02/08.pdf

Smith, K., \& Levin, S. (1995). Walkfit: Chůzi ke zdravi [Walkfit: Walking to health]. Bratislava: Timy.

Sovová, E., Zapletalová, B., \& Cipryanová, H. (2008). 100+1 otázek a odpovédí o chi̊zi, nejen nordické: Chůze pro začátečníky i pokročilé, prevence mnoha onemocnění, slavné osobnosti a chize [100+1 Questions and answers about walking, not only Nordic: Walking for beginners and advanced, prevention of many diseases, celebrities and walking]. Praha: Grada.

Stoggl, T., Lindinger, S., \& Muller, E. (2007). Evaluation of an upper-body strength test for the cross-country skiing sprint. Medicine \& Science in Sports \& Exercise, 39(7), 1160-1169. https://doi.org/10.1249/mss.0b013e3180537201

Survio. (n.d.). Create a survey. https://www.survio.com/en/

Tschentscher, M., Niederseer, D., \& Niebauer, J. (2013). Health benefits of Nordic Walking: A systematic review. American Journal of Preventive Medicine, 44(1), 76-84. https://doi.org/10.1016/j.amepre.2012.09.043

Vahasoyrinki, P., Komi, P. V., Seppala, S., Ishikawa, M., Kolehmainen, V., Salmi, J. A., \& Linnamo, V. (2008). Effect of skiing speed on ski and pole forces in cross-country skiing. Medicine \& Science in Sports \& Exercise, 40(6), 1111-1116. https://doi.org/10.1249/mss.0b013e3181666a88

Wagner, A., Simon, C., Ducimetiére, P., Montaye, M., Bongard, V., Yarnell, J., Bingham, A., Hedelin, G., Ferrières, J., Evans, A., \& Arveiler, D. (2001). Leisure-time physical activity and regular walking or cycling to work are associated with adiposity and 5 y weight gain in middle-aged men: The PRIME study. International Journal of Obesity and Related Metabolic Disorders, 25(7), 940-948. https://doi.org/10.1038/sj.ijo.0801635 